\title{
METHYL ALCOHOL POISONING - A MORPHOLOGICAL STUDY FOR 20-YEARS PERIOD
}

\author{
Burulianova I., V. Konstantinova*, D. Radoinova \\ Department of Forensic Medicine, Department of General and Clinical pathology*, Varna Medical \\ University
}

Reviewed by: Assoc. Prof. D. Radoinova, MD, PhD

\section{INTRODUCTION}

The clinical manifestations of methanol poisoning have been the subject of several review articles over the past forty years $(2,11)$, though detailed postmortem pathologic studies are relatively few. The earliest autopsy studies on methanol poisoning have emphasized the acute changes secondary to hypoxic or ischemic injury to the gray matter, cerebral oedema and acute neuronal injury. Postmortem studies of individuals, who survive intoxication several days or weeks have shown brain injury characterized by bilateral putamen necrosis, particularly affecting the lateral portions of the nuclei $(1,10)$. In some of the cases there has also been a dramatic pattern of white matter hemorrhagic necrosis, involving the centrum semiovale, especially affecting subcortical regions /10/. The precise mechanism of methanol toxicity remains a matter of debate $/ 2 /$. The observed lesions represent direct toxic effects of methanol and its metabolities and injury, secondary to anoxia and acidosis. Injury to the putamen likely represents a selective toxic effect, possibly potentiated by poor venous drainage. The pathogenesis of the white matter hemorrhagic necrosis remains unexplained $/ 6 /$.

\section{MATERIAL AND METHODS}

The aim of this study was to examine morphological changes in the internal organs in methyl alcohol poisoning cases. The records of the Forensic Medicine Department in Varna Medical University were reviewed retrospectively for 20-years period - from 01.01.1986 to 01.01.2006. There were 16 methanol poisoning from 8028 autopsies or $0,2 \%$. The victim's sex was mainly male -14 men $(87,5 \%)$ and only 2 woman $(12,5 \%)$. The age of men varies from 30 to 66-years, woman are 50 and 52-years old. The content of methanol in blood varies from $0,104 \% \mathrm{o}$ to $3,05 \% \mathrm{o}$ in 52 -old woman. We performed microscopical examinations in 7 cases $(43,75 \%)$, in which there were blocks on disposal.

\footnotetext{
Address for correspondence:

Irina Burulianova, Department of Forensic Medicine, Medical University Prof. Dr. Paraskev Stoyanov, 55 Marin Drinov St, BG-9002

Varna, BULGARIA

e-mail: burulianova@abv.bg
}

\section{RESULTS}

There were cerebral perivascular and pericellular oedema, congestion, severe degenerative changes in most cases, particularly around vessels (in one case there were focuses of encephalomalacia), arteriolar hyalinosis in some vessels (in most cases). There was a loss of Purkinje cells in the cerebellum in one case and pseudocystes in other case. The histological changes in lungs were: microhaemorrhages in alveoles, congestion, oedema, pulmonary emphysema, atelectases, haemosiderin-laden macrophages. Microscopical changes in the myocardium include interstitial oedema, congestion, myocardiofibrosis, focal lipomatosis, hyalinosis in the arterioles. The most prominent changes were in liver-different kind of fatty degeneration, hydropic degeneration, hyperemia, intrahepatal cholestasis, hyalinosis of the arterioles. We found severe renal tubular degeneration in kidney, capilary dilatation and congestion. There was congestion in the other organs.

\section{DISCUSSION}

Our results showed that the most frequent changes were: fatty degeneration in liver, intrahepatal cholestasis, cerebral oedema, degeneration around brain vessels, hyalinosis, interstitial oedema, lipomatosis, congestion in the myocardium, renal tubular degeneration, microhaemorrhages in alveoles, haemosiderophages, pulmonary oedema, emphysema, atelectases. Most authors revealed the same changes. Except these histological changes, they investigated putamen, caudate nucleus, pontine tegmentum and optic nerves and found necrosis and haemorrhages $(3,4,7,8,9)$. Retinal damage is believed to be due to the inhibition of retinal hexokinase by formaldehyde an intermediate metabolite of methanol. In one case we observed pseudocysts in brain. The same were Mc Lean's results (5). Autopsies revealed cystic resorbtion of the putamen and the frontocentral subcortical white matter in addition to widespread neuronal damage throughout the cerebrum, cerebellum, brainstem, spinal cord. In one our case there was the loss of Purkinje cells in the cerebellum. We haven't blocks of optic nerves, putamen, caudate nucleus and pontine tegmentum. We also estab- 
lished degeneration in the parietal area of the brain. Mittal et al. observed degeneration in the parietal cortex in $85,7 \%$ of cases, but putamental degeneration and necrosis in $7,14 \%$ (7).

We didn't meet in literature explaining of the cholostasis. Maybe the mechanism is severe degeneration of the liver cells. According Mittal (7) liver fatty degeneration was seen in $67,8 \%$ and microvesicular fat in hepatocytes-in $42,5 \%$.

\section{LITERATURE}

1. Betta P.G. Forno G (1988) Necrosi emorragica del putamen da intossicazione acuta da alcool metilico. Pathologica 80: 215-218.

2. Bruyn G.W., AL-Deeb S:, Vielvoye G.J.(1994) Methanol intoxication. In: Handbook of Clinical Neurology, Vinken PJ, Bruyen GW, Vol 64, pp 95-106, Eslevier: Amsterdam

3. Gaul, HP, Wallace CJ, Auer RN, Fong TC -MR findings in methanol intoxication, $\mathrm{Am} \mathrm{J}$. Neuroradiol., 1995, 16, 1783-1786
4. Kaye, S.-Insidious methyl alcohol poisoning, Virginia Med. Monthly, 1958, 85, 670.

5. Mc Lean DR, Jacobs H, Mielke BW - Methanol poisoning: a clinical and pathological stugy.

6. Menne FR et al- Final diagnosis - methanol poisoning, Ann.Neurol, 8: 161-167

7. Mittal BV, Desai AP, Knade KR - 28 fatal out of the 97 cases of methylalcohol poisoning, J.Postgrad.Med. 1991, 37, 9-13.

8. Ravichandran RR, Dudani RA, Almeida AF, Chawla RP, Acharya VN - Methylalcohol poisoning (Experience of an outbreak in Bombay), Am.J.Neurol., 1984, 30, 269-274)

9. Sharma HS -Methyl induced optic nerve cupping, Arch.Ophthalmol., 1999, 117:286-287

10. Suit PE, Esstes ML (1990) Methanol intoxication: clinical features and differential diagnosis. Cleve Clin $J$ Med 57:465-471

11. Schneck SA(1979) - Methyl alcohol. In: Handbook of Clinical Neurology, Vinken PJ, Bruyn GW, Vol 36, pp 351-360, Eslevier:Amsterdam 